\title{
Norms for pure desire ${ }^{\&}$
}

\author{
(Normas para el puro deseo)
}

\author{
Víctor M. VERDEJO* \\ University of Valencia
}

\begin{abstract}
According to a widespread, broadly Humean consensus, desires and other conative attitudes seem as such to be free from any normative constraints of rationality. However, rational subjects are also required to be attitude-coherent in ways that prima facie hold sway for desire. I here examine the plausibility of this idea by proposing several principles for coherent desire. These principles parallel principles for coherent belief and can be used to make a case for a kind of purely conative normativity. I consider several objections to a principle for consistent desiring and reply to them. I conclude that, if attitudecoherence is a mark of rationality, the broadly Humean consensus must be rejected.
\end{abstract}

KEYWORDS: desire, belief, rationality, coherence, Hume.

RESUMEN: Segun un consenso a grandes rasgos humeano, los deseos y otras actitudes conativas parecen estar, en cuanto tales, libres de cualquier restricción normativa de racionalidad. Sin embargo, a los sujetos racionales se les requiere también coherencia en sus actitudes de maneras que parecen aplicarse igualmente al deseo. Examino aqui la plausibilidad de esta idea mediante la formulación de varios principios para el deseo coherente. Estos principios son paralelos a principios para la creencia coherente y pueden usarse para argumentar a favor de un tipo de normatividad puramente conativa. Considero y respondo a algunas objeciones a un principio para el deseo consistente. Finalmente, concluyo que, si la coherencia en las actitudes es una marca de racionalidad, el consenso humeano debe ser rechazado.

PALABRAS CLAVE: deseo, creencia, racionalidad, coherencia, Hume.

\& I am grateful to two anonymous referees for their very insightful comments on an earlier draft. This research has been developed with the generous support of the Ministry of Economy and Competitiveness (Government of Spain) and the European Union via the financed projects FFI2016-80588-R and FFI2015-63892-P (MINECO, AEI/FEDER, EU), as well as the Secretary for Universities and Research of the Department of Economy and Knowledge (Government of Catalonia).

* Correspondence to: Víctor M. Verdejo. LOGOS Research Group/BIAP (Barcelona Institute of Philosophy)/University of Barcelona. Montealegre 6-8, 4th floor, 08001, Barcelona (Spain) - vmverdejo@gmail.com - https://orcid.org/0000-0002-7872-0206

How to cite: Verdejo, Víctor M. (2020). «Norms for pure desire»; Theoria. An International Journal for Theory, History and Foundations of Science, 35(1), 95-112. (https://doi.org/10.1387/theoria.19624).

Received: 3 May, 2018; Final version: 19 June, 2019.

ISSN 0495-4548 - eISSN 2171-679X / (c) 2020 UPV/EHU

This article is distributed under the terms of the

Creative Commons Atribution 4.0 Internacional License 


\section{Introduction}

The appeal to beliefs and desires-or more generally, doxastic and conative states-is a commonplace in the philosophy of mind and the essence of common sense or folk psychology. Many authors have engaged in the difficult project of elucidating the nature and individuation of desire. Candidate accounts include the view that desires involve a distinctive, world-to-mind direction of fit (Searle, 1983) and approaches in terms of belief (critically discussed in Lewis, 1988, 1996), judgments or appearances (Scanlon, 1998; Oddie, 2005), causal histories or functions (Millikan, 1986), dispositions (Stalnaker, 1984; Smith, 1994), second-order attitudes (Humberstone, 1992), and more besides. In what follows, I will not adjudicate the question of which one of these approaches, if any, would offer a satisfactory elucidation of the nature of desire. For present purposes, I will be assuming a primitive and all-embracing notion of propositional desire. Desire, so understood, is to be roughly located in between (and therefore distinguished from) mere appetites or impulses, on the one hand, and self-conscious or self-reflective evaluative judgments, on the other.

Although many discussions concern the nature and individuation of desire, no similar interest might have arisen thus far about the normativity associated with this attitude type as such. Consider Theresa's case as an illustration of the issue at stake. Theresa is a remarkably educated person of our time who is admired for her outstanding political knowledge. She is, nonetheless, lately and frequently caught with attitudes she would (sincerely) express with utterances of (a) and (b):

(a) I desire that Britain leave the European Union.

(b) I desire that Britain remain in the European Union.

Theresa enjoys an extraordinary lucidity, as she is able to adduce all sorts of convincing reasons for justifying her utterances of (a) and (b) on every occasion. Still Theresa's friends and acquaintances do not think Theresa is entirely as she should be, and, after finding out about this pair of persisting desire reports, they have ceased to take her seriously on this matter. They think she should be able to have and express desires in a more consistent manner. A preliminary explanation of this comes readily to mind: desires may as such be subject to certain rationality norms that prevent flagrant inconsistencies of the sort Theresa exhibits. If this explanation were sound, Theresa's story would be an example of violation of rationality norms for desiring as such, or as I will be saying interchangeably, pure desire.

It is, however, controversial whether there are any such rationality norms for pure desire. Indeed, a particularly dismissive consensus seems to have dominated the consideration of these norms to date. We might take David Hume as voicing this consensus when he famously observed that:

'Tis not contrary to reason to prefer the destruction of the whole world to the scratching of my finger. 'Tis not contrary to reason for me to chuse my total ruin, to prevent the least uneasiness of an Indian or person wholly unknown to me. 'Tis as little contrary to reason to prefer even my own acknowledg'd lesser good to my greater, and have a more ardent affection for the former than the latter. (Hume, 2006, p. 62) ${ }^{1}$

1 I follow Broome (2013, p. 194) in interpreting Hume's quotation with the mass noun 'reason', as a claim about rationality and not as an implausible claim about the total lack of reasons to prefer or de- 
In briefest outline, the Humean credo on this score is that "an agent's ends and values are set by the agent's desires and not by a special organ of reason" and, hence, "cannot be criticized as contrary to reason because they are not determined by reason" (Weller, 2013 , p. 5). Leaving aside exegetical matters, and although this credo may come in a variety of shapes and qualifications in contemporary theorising, the general idea pervades that while beliefs are, all too plausibly, subject to norms of rationality-and very especially, norms to believe what is true-no genuine norms or normative constraints would seem to hold for desiring as such or pure desire. As far as desire is concerned, anything seems to go.

This idea is initially plausible: desires may well be rational or irrational in the light of several practical, social, moral or religious considerations. But how could there be rationality norms for desiring as such, that is to say, once those considerations are factored out? Many would indeed be ready to credit the view that there could not be any such norms of rationality for pure desire.

One can find traces of this kind of scepticism about rationality norms for pure desire in the writings of prominent scholars who differ in just about everything else. According to their views, rationality norms for desiring stem, if at all, from considerations other than desire itself. As Michael Smith observes, it is for instance common to accept as "the standard picture of human psychology" that desires are "not subject to any sort of rational criticism at all", or rather, that they are so subject to rational criticism "only insofar as they are based on beliefs that are subject to rational criticism" (Smith, 1994, p. 8). ${ }^{2}$

The view is not particularly attached to the idea that desires involve reasons. Some writers would accept that there are reasons to desire but deny that desires themselves are reason-providing. On these views as well, desires are rationally sanctioned only insofar as they meet or fail to meet some condition beyond mere desiring. Thomas Scanlon, for instance, would restrict irrationality of one's desires to cases in which "a person fails to respond to what he or she acknowledges to be relevant reasons" (1998, p. 25). Similarly, Derek Parfit (2001) holds that the rationality of one's desires depends upon one's beliefs about the reason constituting facts.

The same spirit inspires the work of authors whose conception of rationality is not so tied to reasons. John Broome, for instance, acknowledges that he is not convinced "there is any correct reasoning to be done with desires" (2013, p. 268), where reasoning is taken to be a mental activity by which we come to satisfy the requirements of rationality. In the context of his influential discussion about the normativity of content and belief, Paul Boghossian expresses a similar scepticism by admitting that it is not clear to him "that there are norms on desire merely qua contentful state" (Boghossian, 2008, p. 103).

sire. In this paper, my focus is on desire even though there are obvious points of contact with the comparative notion of preference (see Broome 1999a for discussion).

2 Intention would seem to align itself with belief on this count. Admittedly, both intention and belief exhibit crucial connections to desire and both seem to be subject to substantial rational constraints. Nonetheless, it is usually found natural to assume that "intentions are subject to rationality norms that do not apply in the same way to ordinary desires" (Bratman, 2009, p. 412; see also Bratman, 1987). I will discuss Bratman's views in more detail in Section 4. 
In sum, the broadly Humean consensus takes it that desires as such are free from rational sanction or that there is no norm of rationality according to which desire as such can be determined to be correct or incorrect. We may state the consensus as in (C):

C. Desires, qua propositional states, are not subject to any norms of rationality.

In this paper, I set out to show that $(\mathrm{C})$ is at odds with a baseline conception of rationality as tied to attitude-coherence and must therefore be rejected in the account of conative normativity. In the next Section 2, I discuss some views related to (C) that are, however, independent of its assessment in this paper. I go on, in Section 3, to (i) argue that rational subjects are required to respect basic content-relations involved in grasping the propositional contents individuating one's attitudes in ways that prima facie hold sway for desire, and (ii) introduce, in accordance with (i), some candidate principles for coherent desire which parallel principles for coherent belief and can be used to make a case for a kind of purely conative normativity. I then consider several objections to a principle for consistent desire and reply to them in Section 4 . I conclude, in the final Section 5, that since the idea that attitude-coherence is a mark of rationality remains unchallenged in the case of desire, (C) must be dismissed.

\section{Demarcating pure desire}

Before we proceed, however, we must demarcate (C) more precisely. Note, to begin with, that the appeal to 'norms of rationality' (or interchangeably, 'rationality norms') in (C) does not presuppose that rationality is itself normative or that there is normativity beyond reasons (cf. Kolodny, 2005). For present purposes, all that (C) requires is that the target norms are norms conformity with which is a mark of rationality. One can accept the existence of such norms while denying that rationality is normative or that norms, so conceived, constitute themselves reasons to desire. Several other qualifications are needed for a careful consideration of (C). I deal with them in the remainder of this section.

Firstly, (C) must be sharply distinguished from two other Humean theses to which it is historically and conceptually related. The first of these is that motivating reasons (featuring paradigmatically in practical reasoning) are or involve in every case ultimate or intrinsic (as opposed to motivated or reason-based) desires or, relatedly, the thesis that response to normativity is always based on desire (see e.g. Finlay, 2007; Schroeder, 2007 or May, 2013 for discussion). Although both views share a root in Humean developments, $(\mathrm{C})$ is a claim about norms or normative reasons (for desire) - viz. about whether S has obligations stemming from desiring-and does not entail nor is entailed by any particular view about motivating reasons - viz. about what makes $S$ have reasons that guide or explain $S$ 's behaviour.

The other Humean thesis in the vicinity of $(\mathrm{C})$ is the one that says that belief and desire are separable, independent existences or the related thesis that the desirability of a proposition is independent of its truth (Stefánsson, 2014). Standard articulations of (C) may appeal to the fact that, in the case of desire, there is nothing playing the normative role that truth plays in the case of belief. However, one needs not embrace (C) for precisely this reason and various views about the normativity of belief and its relation to desire are compatible with (C). Nothing of what follows therefore bears directly on the assessment of these much debated Humean theses, and we can put them to one side for present purposes. 
Moreover, (C) does not entail that desires are not rationally constrained at all or that there are no norms of rationality that would ever affect a subject's desires. These claims are certainly implausible. There are several ways of articulating rational norms for desiring and desire revision compatible with (C), such as standard forms of realism about value. Consider the view that rational subjects ought to desire what is good. It follows from this view that whether or not one ought to have a particular desire would depend on what the good is. Nothing follows however regarding what one ought to desire by the mere fact that one has a certain desire. The thesis targeted in this paper-viz. (C)-concerns the latter question. Note, relatedly, that $(\mathrm{C})$ is not directly against the existence of vertical norms for desire such as the norm that subjects ought to desire what is good, or valuable or pleasant, or that desires ought to aim at satisfaction. (C) is against these norms (a) being norms of rationality (as opposed to, say, norms of practical utility) and (b) being norms that apply to desires qua desires.

Patently, (C) does not say that there are no rational (or irrational) desires or what Robert Audi and others call 'intrinsically (ir)rational' desires or wants (Audi, 2001, p. 68). The thesis says that there are no norms for rational desire as such. This might be so independently of whether we can also make room for a notion of intrinsically rational or irrational desire, that is to say, a desire whose properties turn on necessary conditions of a subject's rationality. ${ }^{3}$ Consider, for instance, the desire for one's own survival. Arguably, possession of this desire is a necessary condition of rationality. It does not follow from this that there are any norms of rationality in the sense of (C). In particular, it does not follow that there is a desire-norm to the effect that one ought to desire one's own survival. The existence of (ir)rational desires is compatible with (C) insofar as the (ir)rationality of one's desires is not taken to involve norms for desiring as such.

It is also clear that (C) is blind about whether the alleged norms for pure desire are distinctive, let alone essential to the attitude of desire. The view under scrutiny is whether there are any norms of rationality that apply to pure desires, and not whether those norms are actually essential to or determinative of the attitude itself (as defended e.g. in Zangwill, 2010). The latter is an additional claim that must be backed by further argument.

Finally, and crucially, the present discussion is orthogonal to the question about the existence of normative relations holding between desires and other attitudes such as belief and intention. Many authors would be ready to accept the existence of such cross-attitudinal norms (cf. Audi, 2001; Schafer, 2013). The view targeted in this piece, however, is that there are no rational norms for pure desire that would follow merely from the fact that a subject has a desire or set of desires. It is in this sense that the present discussion is concerned exclusively with purely conative normativity.

\section{Purely conative normativity}

Once the consensus is carefully delineated, I would like to present some normative principles that stand against $(\mathrm{C})$ and explicitly articulate the idea that there are norms of ration-

3 See Hubin (1991) for a defence of the view that there are no intrinsically irrational desires in the context of action. 
ality for pure desire. This is not a totally unexplored territory. Some authors have already proposed principles that, at least to some extent, could be used to challenge the target consensus, such as recent Moorean analysis of norms of rational desire (Wall, 2012; Williams, 2014). In this piece, I would like to approach the issue from a more general, albeit self-contained angle.

Now, attitude-coherence is very often considered to be a mark, and even the hallmark of rationality. While its roots probably trace back to Aristotle, ${ }^{4}$ it is not hard to find recent and influential expressions of this idea. John Broome, for instance, observes that:

What rationality requires of you is proper order in your mind. It requires your mental states to be properly related to each other. That is to say, it requires your mind to be coherent in particular respects. (Broome, 2013, p. 152)

According to Broome and many others, the study of these specific requirements of attitudecoherence is supposed to give us insights into the very nature of rationality. ${ }^{5}$ The requirements of attitude-coherence typically concern the deductive relations that hold among contents of attitudes of the same type (as when one is required to avoid contradictory beliefs) and also content-based relations among attitudes of different type (as when one is required to intend what one believes one ought to intend). Candidate exemplifications of the marriage between rationality and coherence include principles of theoretical and practical reasoning involving belief, intention, and the relations between belief, desire and intention (see Verdejo, 2017a and Verdejo \& González de Prado, manuscript for discussion). So understood, coherence is an acknowledged mark of rationality even for those who restrict normativity to reasons and reject norms or requirements of coherence as such. Niko Kolodny, for instance, agrees that "it is relatively clear how we might settle questions about what rationality requires; it is whatever is necessary for coherence" (Kolodny, 2005, p. 511).

How does this general view affect the consideration of desire though? One might of course wish to deny that attitude-coherence is ever a mark of rationality or suggest, more plausibly, that even if attitude-coherence is generally a mark of rationality, desire is to pose a central exception. What we seek is thus to shroud the idea that desire-coherence is a mark of rationality in enough plausibility to get the discussion off the ground. The argument I am setting out is thus of a conditional form. If one does accept that attitude-coherence is, on the face of it, a mark of rationality in the case of desire and we can, in the light of this initial plausibility, adequately explain away alleged counterexamples, we may therefore make a strong case for the rejection of $(\mathrm{C})$.

There is, I believe, a fundamental reason to support the initial plausibility of the view that attitude-coherence is a mark of rationality and is so also in the case of desire. This reason has to do with the rational capacities of a subject who grasps the basic content-relations

4 Aristotle's principle of non-contradiction (Metaphysics IV, 3-6) can be seen, for instance, as a clear anticipation of the contemporary understanding of the relation between coherence and rationality.

5 Broome takes requirements of coherence to be in harmony with Thomas Nagel's observation that " $[\mathrm{r}]$ ationality can be defined only in terms of adherence to rational requirements. One cannot discover or justify the principles which specify those requirements by deriving them from the concept of rationality, since it is precisely those requirements which define the concept, and they must be rendered plausible as requirements independently" (Nagel, 1970, p. 20; cited in Broome, 2013, p. 150). 
attached to a content $\mathrm{p}$ that individuates an attitude. A subject that is not sensitive to such basic content-relations, it would seem, is ipso facto a subject vulnerable to the charge of lack of understanding of $\mathrm{p}$, and hence of lack of the putative attitude (and indeed any attitude) towards $p$. Desire is a case in point. Consider for instance the desire that the wall be green. A rational subject that genuinely has that desire vis-à-vis any other desire-say, the desire that the wall be destroyed-ought to have (or acquiesce to attributions of) the desire that the wall be a certain colour (assuming, that is to say, that the subject grasps all the relevant concepts). The reason for this is that it is a very basic content-relation in which the content that $x$ is green stands that, for any $x$, it entails the content that $x$ is a certain colour. Note that we may but do not really need to resort to the notion of analyticity to make the point. The point concerns sensitivity to very basic content-relations between propositions containing the concepts green and colour. A subject who at the same time avows the desire that the wall be green but not the desire that the wall be a certain colour, would seem to lack understanding of the propositional contents involved or lack the basic rational capacities of a subject that genuinely desires that the wall be green.

Although desire is the attitude of concern here, it is not the only type of attitude for which rational subjects are plausibly bound by sensitivity to basic content-relations in this sense. They include a good number of what we may call 'affirmative' attitudes (such as belief, intention or hope), 'negative' attitudes (such as reject, dislike or hate) or 'agnostic' attitudes (such as doubt or wonder) (Verdejo \& González de Prado, manuscript). In all such cases, it seems correct to suppose that basic forms of attitude-incoherence with respect to rationally A-ing that $\mathrm{p}$ on the part of a subject $S$ undermines the status of the subject as a subject that is genuinely $\mathrm{A}$-ing that $\mathrm{p}$-as opposed to A-ing any $\mathrm{q}$ distinct from $\mathrm{p}$ (or indeed not A-ing anything at all). This is hardly surprising: to $\mathrm{A}$ that $\mathrm{p}$ is to bear an attitude towards a certain content. But how are we to make sense of the fact that it is precisely $\mathrm{p}$ that one is A-ing towards if no content-restrictions are in place?

Take for instance the attitude of rejection towards the proposition that the wall is coloured. A rational subject that rejects that proposition ought to also reject the proposition that the wall is green and do so, again, in virtue of grasping basic content-relations in which that proposition stands (note that the converse is not true: one might very well reject that the wall is green without rejecting that the wall is coloured).

Thus, although belief is our preferred example of coherent attitude (in ways to be spelled out below), nothing here sanctions the view that attitude-coherence would always involve, for any attitude, principles that mimic or are structurally analogous to principles for belief. To illustrate, I think it is plausible that to doubt whether $\mathrm{p}$ would rationally require one to doubt whether not-p (Verdejo \& González de Prado, manuscript). This is the structural opposite of the consistency norm for belief (see below). Similarly, to dislike that $\mathrm{p}$ and $\mathrm{q}$ will not in any case require one to dislike that $\mathrm{p}$ (say, because it is quite on the cards that it is $\mathrm{q}$ but not $\mathrm{p}$ the one a subject might really be disliking). If correct, this shows that conjunction equivalence is not a norm to be preserved for any attitude whatsoever. I have in fact argued elsewhere that norms that hold for desire are distinctive and respond to a specific domain of rationality (see Verdejo, 2017b) and thus am ready to accept that norms governing belief may not apply or not apply in the same way to desire.

If one sees any plausibility in this line of argument, one should also accept that norms of conative coherence or desire-coherence are, on the face of it, norms of rationality. Importantly, conative coherence, so understood, might be only a pro tanto (as opposed to pro 
toto) condition of rationality: in being conatively incoherent one is less than fully rational but one may indeed fail to be conatively coherent on a certain occasion and still be on the whole rational. I shall return to this point below. ${ }^{6}$

In the remainder of this section, I shall begin to put this leading thought into practice by introducing some plausible candidates of conative principles by analogy to widely held rationality principles for belief, together with some basic caveats. In the next section, I shall consider a number of objections to the most discussed of these principles regarding consistency and conclude that, thus far, there is no obvious reason to banish conative coherence norms from the family of genuine rationality norms.

Let us therefore take a leaf from the analyses of three widely accepted normative principles for belief. They can be stated using the monadic belief operator 'B' as holding for any subject $S$ and propositions p or q. Versions of the following principles are usually accepted in contemporary theorising about rationality and its requirements (e.g. Reisner, 2011; Broome, 2013, Chap. 9).

$$
\begin{aligned}
& \text { Consistent Belief. S ought to (not } \mathrm{B}(\text { not } \mathrm{p}) \text { if } \mathrm{S} \mathrm{Bp}) \\
& \text { Doxastic Modus Ponens. } S \text { ought to }(\mathrm{Bq} \text { if } \mathrm{S} \mathrm{Bp} \text { and } \mathrm{B}(\text { if } \mathrm{p} \text { then } \mathrm{q}) \text { ) } \\
& \text { Belief Conjunction Equivalence. } S \text { ought to }(\mathrm{Bp} \text { and } \mathrm{Bq} \text { iff } S \mathrm{~B}(\mathrm{p} \text { and } \mathrm{q}) \text { ) }
\end{aligned}
$$

To the extent that doxastic coherence is one of the marks of a subject's rationality, these principles bring out norms of rationality in the relevant sense: norms conformity with which is a mark of rationality. However, several qualifications are usually made in order to attain maximally plausible versions of these principles.

To begin with, and as the parenthetical notation makes explicit, the principles assume wide-scope readings of the 'ought'-relation. This prevents obvious counterexamples. A narrow scope reading of Consistent Belief ( $\mathrm{CB}$ henceforth), for instance, would lead us to conclude that subjects have obligations not to believe something true, whenever $\mathrm{p}$ is false. This is implausible even if one rejects the popular view that correct belief is true belief. We can easily avoid this result on a wide scope interpretation. So interpreted, the principles do not express obligations to have particular beliefs-hence, no obligation not to have any particular true belief-but, differently enough, obligations to respect coherence relations among one's beliefs (Broome 1999b, 2013).

As reflection promptly shows, accuracy would require us to introduce further caveats for the sake of plausibility. For instance, first, the principles must be typically indexed with a time or context, that is to say, the principles state obligations relative to a time or context and not all things considered or timeless belief-obligations for a subject $S$. Most obviously, $\mathrm{CB}$ for instance must not be read as entailing that subjects cannot change their minds or that they cannot ever hold contradictory beliefs over time. Plainly, one is rationally allowed to believe, at $t$, that David is a capable politician and also believe, at some time $t+n$, that David is not a capable politician.

6 I have also argued elsewhere that coherence is not the sole mark or hallmark of rationality when it comes to attitudes. In some cases-e.g. when there are rational desires one ought to have such as the desire for one's own survival-rationality might require incoherence in order for you to be on the whole rational (Verdejo, 2017a). The discussion in this paper can however proceed whether or not one accepts this view. 
Secondly, in order not to get undesired results, the principles need be usually constrained with the proviso that $S$ cares about or brings somehow into consideration that $p$ or q. This is clearly the case in the analysis of Doxastic Modus Ponens. The norm is highly implausible if interpreted as requiring that subjects have an obligation to actually believe that $\mathrm{q}$ for every $\mathrm{q}$ that is entailed by $\mathrm{p}$, given that one believes $\mathrm{p}$. One may believe that I have drunk some water or left the room without thereby believing that I have drunk some $\mathrm{H}_{2} \mathrm{O}$ or that I have spatio-temporal properties. One may simply lack the ' $\mathrm{H}_{2} \mathrm{O}$ ' - or 'spatio-temporal property'-concepts that would permit consideration of the latter beliefs in the first place. This is so in spite of the fact that the former belief contents would seem to entail the latter. There is nothing irrational in this combination of beliefs.

In the third place, it is also a psychologically plausible requirement that the propositional contents are presented to $S$ in a straightforward or not involuted way, one which makes plain the relevant formal or deductive relations among S's beliefs. I may believe that there is a glass of gin and tonic in front of me but, anyhow, dissent to someone's asserting that there is a glass of gin or that there is a glass of tonic in front of me. This would be compatible with compliance with Belief Conjunction Equivalence if the corresponding expressions were disambiguated. On a charitable interpretation, I would rationally be disbelieving that there is a glass of gin alone and a glass of tonic alone. In many cases like this, apparent failures to respect the principles can be attributed to the lack of perspicuity of the (expression of the) contents and not the lack of rationality of the subjects on that occasion.

It is possible that further caveats need to be introduced to avoid counterexamples. Nonetheless, the ones just mentioned should suffice to illustrate the kind of qualifications that bona fide doxastic principles of coherence may need in order to reach maximally plausible statements.

Now, consider the following conative examples which introduce the expression ' $\mathrm{D}$ ' for the attitude of desiring. They parallel the foregoing doxastic principles and would seem to hold for any rational desirer and propositions p or q:

Consistent Desire. S ought to (not $\mathrm{D}$ (not $\mathrm{p})$ if S Dp)

Conative Modus Ponens. S ought to (Dq if S Dp and D(if p then $\mathrm{q})$ )

Desire Conjunction Equivalence. S ought to (Dp and Dq iff $S \mathrm{D}(\mathrm{p}$ and $\mathrm{q})$ )

These principles are also explicitly wide-scoped. On a narrow reading, if, as a result of lack of information or unreliable testimony, I come to desire what, unknown to me, is a highly undesirable $\mathrm{p}$, Consistent Desire (CD from now on) would entail my obligation not to desire that a highly undesirable p does not obtain. This is not reasonable. A wide-scope reading would safeguard the principles from this kind of counterexamples.

As in the case of belief too, conative principles must be indexed with a time and context to be minimally plausible. Consider CD. We must not read it as prohibiting contradictory desires for a rational desirer under any circumstances whatsoever, but only to do so in relation to a particular time or context. It seems perfectly rational, for instance, to desire, at a given time $t$, that David be a capable politician, and, at some other time $t+n$, to desire that David not be a capable politician. CD accommodates this if temporally indexed.

The principles must also be restricted to cases in which subjects care about the featuring propositional contents and these are not involuted or confused. Drinking water or leaving the room, for instance, entails drinking $\mathrm{H}_{2} \mathrm{O}$ or having spatio-temporal properties, re- 
spectively. However, one may very well want me to drink water or leave the room without wanting me to drink $\mathrm{H}_{2} \mathrm{O}$ or having spatio-temporal properties. It would be uncharitable to assume that Conative Modus Ponens entails that one has to desire whatever logical or nomological consequences there are of what one desires, as opposed to those logical or nomological consequences that one considers or is relevantly aware of.

Likewise, Desire Conjunction Equivalence should be restricted to cases in which the corresponding conjunctive form is transparent to the desirer. On a Friday evening, I may express my desire to have a gin and tonic but may show reluctance towards someone offering me a glass of gin, or someone offering me a glass of tonic. However, what I would be refusing in such a case is not exactly to have gin or to have tonic. Rather I would likely be refusing (wanting not) to have gin alone or tonic alone. All the same, if my desire for a gin and tonic is genuine, I certainly should want to have, on the one hand, gin, and, on the other hand, tonic (in the same cocktail glass). When confronted with perspicuous and unambiguous statements of my desires, it seems more plausible that I will comply with Desire Conjunction Equivalence if $\mathrm{I}$ am to be a rational desirer.

Once precisely stated, all three conative principles turn on plausible coherence relations among one's desires. But coherence is, as we are assuming, an initially plausible mark of a subject's rationality. Thus, if these purely conative normative principles are sound, even approximately so, they raise a prima facie case against $(\mathrm{C})$. They inform the claim that if $S$ has a desire that $\mathrm{p}, \mathrm{S}$ is ipso facto bound by rationality norms concerning the coherence of one's desires.

Note that the fact that these principles hold, granted that they do indeed hold, can receive a number of explanations. Some authors would see them as a consequence of the commitments or the reasons specific to desire. Others would see them as a consequence of rational vertical norms or obligations to desire what is ideally or objectively desirable. Still others would see them more like norms or requirements which are not to be explained in terms of reasons or rationality, but which must be taken as given and themselves throw light upon the nature of rationality in desire. Here we can take these principles directly at face value as initially plausible norms of rationality for pure desire, without needing to take a stand on their explanation. The situation, once again, parallels the consideration of more discussed principles for pure belief, such as the ones considered earlier in this section. One need not offer a full explanation of these doxastic principles in order to judge that they are plausible normative principles of rationality governing belief.

\section{Objections to purely conative normativity}

Following the Humean impetus described above, many authors will be ready to cast doubt on the kind of conative principles just limned. They will defend the view that they are not correct conative normative principles by denying that compliance with them is a mark of rationality. More precisely, they will adduce several considerations to warrant a relevant disanalogy between the case of belief and the case of desire and thus prevent in this case the application of the general view that attitude-coherence is a mark of rationality. For ease of exposition, I will only focus on objections to Consistent Desire (CD), although related objections may also be launched against the other two. I will take up and elaborate on suggestions by Michael Bratman, John Williams, Bernard Williams and Patricia Marino. 
However, the discussion in this section should not be taken to yield an even remotely fair assessment of these authors's overall views, whose richness and valuable insights must necessarily escape the scope of this paper. Consider, to begin with, Bratman's observation:

I might, without irrationality, both desire to play basketball today and desire to finish this chapter today, all the time knowing that I cannot do both. This is a sort of conflict that occurs countless times in the life of a rational agent. If, however, my plans include both actions then I am guilty of a criticizable form of inconsistency. (Bratman, 1987, p. 32, emphasis in original)

According to Bratman, ordinary desires, unlike intentions and plans, are "merely potential influencers of action" (Bratman, 1987, p. 16, emphasis in original) and, therefore, contradictory desires are admissible "in the life of a rational agent" insofar as they do not lead to a commitment to inconsistent or incompatible actions and plans. Bratman seems to suggest, therefore, that even though there are norms of rationality in the form of several demands for intention, and desires and intentions are both pro-attitudes, there are no rationality norms for pure desire. This would also hold for the case of predominant desires or preferences (cf. Bratman, 1987, pp. 18-19).

Bratman's quoted passage seems to capture something true, but nothing to undermine CD. First, he might simply be taken to suggest that rational subjects may actually fail to respect CD and still be rational. As advanced in Section 3, pure-desire normative principles like $\mathrm{CD}$ are principles that amount to pro tanto conditions of rationality and not pro toto conditions. To be in (discord or) accord with the principles is a mark of (ir)rationality but does not entail that the subject is on the whole (ir)rational. In particular then, CD does not entail that whoever has contradictory desires on a particular occasion is irrational. CD only entails the much weaker claim that subjects that have contradictory desires on a particular occasion are irrational to the extent that they fail to preserve consistency among their desires on that occasion. In other words, to violate $\mathrm{CD}$ on a particular occasion is to be less than a fully rational desirer on that occasion. In this regard, CD is not at all different from his doxastic cousin Consistent Belief. It is indeed worth emphasising, in agreement with this interpretation of Bratman's quote, that ordinary rational agents would in many cases be less than fully rational in such respects. This is compatible with the truth of CD.

However, Bratman's case is probably meant to show more than this, namely, that rationality does not require of us to be consistent desirers as such, but only insofar as those desires affect intention or belief, the 'really rational' attitudes as it were. According to this reading, Bratman's quote describes a situation in which it is not contrary to rationality at all to have a contradictory or inconsistent pair of desires. However, this interpretation is a nonstarter. For Bratman's is plainly not a case of inconsistent desires. We could formalise it via (1), by introducing the knowledge operator ' $\mathrm{K}$ ':

1. S Dp and S Dq and S K not ( $\mathrm{p}$ and $\mathrm{q}$ )

This is the natural interpretation of Bratman's case, where $p$ stands for the proposition associated with S's desire to play basketball and q the proposition associated with S's desire to finish the chapter. Compare (1) to its purely conative variation (1'):

$$
\text { 1'. S Dp and S Dq and S D not (p and q) }
$$

Patently, unlike (1') which seems a violation of Desire Conjunction Equivalence, (1) does not necessarily involve inconsistent or incoherent desires. One may be drawn to the 
thought that it does by overemphasising and misleadingly extrapolating from the normative role of what one knows or believes. Nonetheless, it is simply not true that my knowing or firmly believing that it is not possible that $\mathrm{p}$ and $\mathrm{q}$, makes my desiring that $\mathrm{p}$ and $\mathrm{q}$ inconsistent. It does not. Let us suppose that $(p$ and $q)=r$. Indeed, it would seem a fundamental feature of desire that one can desire that $\mathrm{r}$, and most passionately so, in spite of being certain that $\mathrm{r}$ is false or impossible (e.g. the desire that one can fly or that one's beloved be immortal). Consider now (2):

\section{S Dp and S Dq}

Genuinely inconsistent desires of the form in (2) - which removes the knowledge particle from (1) - would require that the mutually exclusive character of $\mathrm{p}$ and $\mathrm{q}$-i.e. the truth of not ( $p$ and $q)$ - can be extracted or deduced from the very content of the desires that $p$ and $\mathrm{q}$, as opposed to the contents of what one believes or knows. The clearest case of this is the one in which $\mathrm{q}=$ not $\mathrm{p}$. There are other more interesting cases, such as Theresa's case or the green/colour example discussed above. Consider also (3) and (4):

3. Fiora desires that the table be round and desires that the table be square.

4. Alex desires to be a bachelor and desires to be a married man.

I believe one need not buy in to a controversial conception of content to acknowledge that these cases are possible and would involve inconsistent desires that share the structure with (2). Desire inconsistencies in these cases would not involve appeal to states of knowledge of the subject. All the same, CD seems to offer a correct diagnosis regarding (3) and (4). In particular, it seems correct to suppose that rational desirers ought to avoid this kind of inconsistencies.

Bratman's case is not relevantly like (3) or (4). It appeals to the knowledge of the fact that one cannot have the desires for playing basketball and writing the chapter both satisfied at the same time. But such knowledge does not need affect the contents of the desires themselves. If so, their coherence or consistency would not be compromised. Other examples in Bratman's writings are structurally like (1). Consider the polygamist case, in which a person desires to marry A and to marry B after knowing that she cannot marry both $A$ and B (Bratman, 1987, pp. 137-138). Again, although this pair of desires seems rationally permissible, the case is not one of inconsistent desires because there is nothing in the content of the desire to marry A that would exclude to marry B. ${ }^{7}$

One may try to offer a reconstruction of Bratman's sort of case that meets the right form. Consider, for instance, a variation of the marriage example owed to Neil Sinhababu. He observes that "[i]f you desire to remain single but also desire to marry George Clooney, the fact that you desire inconsistent things doesn't mean there's anything wrong with

7 I think this point makes precise the sense in which there are norms for "avoiding specific recognizably unsatisfiable desires" such as "the desire to be a married bachelor" (Williams, 2014, p. 15). In particular, the kind of recognition in question concerns the content of the desires themselves and specifically not the content of one's knowledge or belief states. In Marino's terms (2009), the recognition would concern modal unsatisfiability of conflicting desires (i.e. the fact that there is no possible world in which the desires can be satisfied), what she calls 'essentially conflicting desires'. 
you, and reflecting on your desires won't make either of them go away" (Sinhababu, 2017, p. 195). Sinhababu's example seems to be of exactly the form as in (2). Hence, if he is right that inconsistent desiring of this sort is rationally permissible, $\mathrm{CD}$ would clearly be on the ropes.

However, the claim that inconsistency is rationally permissible in such a case can be disputed by reflection on conditions of accountability before a rational subject. To show this, let us suppose, in line with the example, that George Clooney is rational and does happen to earnestly pop the question to you: 'would you marry me?'. Let us consider the part of this question that strictly concerns your desire to marry him, namely, 'do you desire to marry George Clooney?'. Now, although this might be a situation in which you can actually have several reasons to justify the desire to marry George (e.g., your passionate love for him) but also the desire not to marry George, or anybody else (e.g., your strong liberal stance on the institution of marriage), this would not yet be a situation in which you can rationally claim to have the desire to marry George and not to marry George. In particular, this is not an answer George is likely to find reasonable. If conflicting reasons enter into your appraisal of George's proposal and do so with equal strength, the rational reaction to the question would be perhaps to say that you do not know, really really, whether you desire to marry George, but not to claim —as Sinhababu would have it - that you desire to marry but also, as it happens, not to marry him. Good old George wouldn't let you get away with that!

Another way of making the point is as follows. The described situation can be glossed as one in which you disagree with yourself over the desirability of marrying George. The reason is that if a subject endorses the desire to marry George and a distinct subject the desire not to marry George, it seems unobjectionable that they will be disagreeing over the desirability of marrying George. But it seems implausible to suppose, in harmony with Sinhababu's example, that fully rational subjects would ever disagree with themselves in this way.

Sinhababu's case may be seen as involving conflicting reasons to desire or a conflict in instrumental desire (i.e. desire that is a means to a desired end): you have reasons to desire to marry George (as a means towards being close to your beloved) and not to marry George (as a means towards dodging a crooked institution). Although one may deny that there are instrumental beliefs in the same way in which there are instrumental desires, there is nothing in this kind of case that is relevantly different from the doxastic counterpart, Consistent Belief. In particular, one can also have reasons to believe that $\mathrm{p}$ (say, that one should marry handsome and rich celebrities like George), and reasons to believe that not $\mathrm{p}$ (say, that one should not marry anyone). It does not follow that one has ever reasons to believe that $\mathrm{p}$ and believe not $\mathrm{p}$ or that one is rational in so believing. If coherence is a mark of one's rationality, one is required to endorse at most one of these beliefs after considering all the reasons available. This point seems to unproblematically carry over to the conative case (viz. one can have reasons to desire that $\mathrm{p}$ and reasons to desire that not $\mathrm{p}$ but no reason to desire that $\mathrm{p}$ and desire that not $\mathrm{p}$ ). The consideration of reasons for desire does not, on its own, make a difference. Unless further considerations are adduced, CD still stands as a plausible mark of rationality.

John Williams's Casanova example may be thought to be a better candidate to threaten CD:

When Casanova wanted to seduce a woman, he was well aware that the satisfaction of this desire would be more piquant should there be obstacles to overcome along the way. He knew that 
the thrill of the chase demands the frustration of more immediate desires. There was nothing irrational in his wanting these desires to be frustrated. (Williams, 2014, p. 18)

It would seem clear that Casanova can therefore be taken to hold the desire that he be denied the kiss - in order to increase pleasure in the future - and the desire that he not be denied the kiss-precisely the one he desires to be frustrated now. This, Williams contends, is a contradictory pair of desires. However, "a fuller description of the case is that Casanova wanted to be denied the kiss as a means of heightening his intrinsic desire for it" and "it need not be irrational to hold contradictory desires at least one of which is instrumental" (Williams, 2014, p. 19).

Williams's point seems to me to be independent of the distinction between instrumental and non-instrumental desires or the appeal to heightened desires. It probably suffices to claim that Casanova's conative situation is one which is the potential outcome of sound reasoning. It certainly seems correct to suppose, as Williams does, that Casanova is not irrational in such a situation.

However, I dispute the claim that Casanova's situation is precisely one in which he desires inconsistently that $\mathrm{p}$ and not $\mathrm{p}$. If used as against $\mathrm{CD}$, the case trades on a temporal ambiguity. We have seen that temporal indexes are needed when considering plausible statements of consistency norms. It seems thus natural to suppose that, at $t$, Casanova wants to be denied the kiss, but, at some future time $t+n$, when the loving experience is anticipated to be livelier, will want not to be denied the kiss. Consistently with CD, Casanova's need not be seen as a situation in which, at $t$, he also wants not to be denied the kiss. On a charitable interpretation, if there is rationality in his combination of desires, there must be only one thing he desires at $t$, namely, to be denied the kiss. This is a consequence of his promising expectations regarding $t+n .{ }^{8}$

Let us now move on to the work of another Williams. Bernard Williams raises two sorts of considerations when discussing the distinction between conflicting beliefs and desires in his popular paper 'Ethical Consistency'. Each one can be taken to ground, when suitably supplemented, an objection against CD. First, he points out, plausibly enough, that one may (and arguably may be rationally allowed to) have conflicting desires in virtue of the fact that the same object has desirable and undesirable features (1973, pp. 167-168). It certainly seems reasonable to think that subjects have contradictory stances as a result of the advantageous and disadvantageous features of one and the same object. However, the case in which $S$ wants $x$ (because $x$ has such and such advantageous features) and $S$ wants not- $x$ (because $x$ has at the same time such and such disadvantageous features) is very obviously not a case in which $S$ has contradictory desires of the sort that would threaten $C D$, but a case such as (5):

\section{SDp and $S \mathrm{D}$ (not $\mathrm{q})$}

8 Williams also introduces the case of the gourmand who may, in the terms he proposes, request to her cook to continue the frustration of her desire to eat so that she gets her appetite sharpened (Williams, 2014, pp. 18-19). Clearly, such a request is not irrational. However, when properly analysed, the gourmand does not seem to have inconsistent (but rational) desires at the same time: in order to improve or intensify her gustatory experience she wants not to eat now but will definitely want to eat in the near future. 
The cases involve a subject who desires certain features (say, the perfume of a rose) and does desire that certain other features of the same object do not obtain (say, the thorns of the rose). Thus, the fact that an object has conflicting properties of desire does not force us to conclude that subjects may have rationally admissible contradictory desires.

Bernard Williams also gestures at the possibility of some desires of this sort being such that desirable and undesirable features of the object are the same, cases of what he calls "ambivalence" (Williams, 1973, pp. 168-169). These cases would seem to put pressure on CD. This is suggested by Patricia Marino (2009) according to whom ambivalence involves genuinely conflicting desires which are rationally unobjectionable and not reducible to cases in which the conflict is explained away by appeal to different aspects of the object or situation. For instance, I might wish that my friend will win the competition (because I rejoice in the success of those dear to me) and also wish that she will not win (because I am also being considered for the prize) (cf. Marino's version of Patricia Greenspan's example 2009, \$2).

Ambivalence cases are, if genuine and rationally unobjectionable, fatal for the proponent of norms for pure desire. One may deny that cases of ambivalence are indeed genuine (Brink, 1994), but this is not the line of reply that I would like to pursue here. I do not believe, however, that ambivalent desires ultimately make the day for the advocate of $(\mathrm{C})$. For one may dispute that, even if reasonably possible or even frequent, genuine ambivalence is rationally unobjectionable. The reason echoes our previous point about accountability before a rational subject. Let us suppose, in terms analogous to the Clooney case above, that our friend-let us call it Pat-approaches us to enquire: 'do you want me to win the competition?'. When so confronted, it seems to me, one will not find reasonable to answer Pat's question by avowing a desire that she wins and also does not win the competition. Again, one's reasons to desire might be all mixed up in such a way that one does not really know what one desires. But to express that one has both inconsistent desires would leave Pat scratching her head (assuming of course that she has seriously posed the question). This is only to be expected if CD holds. If attitude-coherence is a mark of rationality-if rationality distinctively requires "proper order in your mind" as Broome puts it—an ideal and fully rational desirer should not violate $\mathrm{CD}$ and one should not thereby be openly caught with ambivalent desires (as opposed to conflicting reasons to desire over which one has not yet made up one's mind).

Theorists may of course wish to see one's commitment to attitude-coherence as, in fact, "overridable, pragmatic and agent-relative" (Marino, 2009, p. 285). But this is just to suspend and beg the question against the view that attitude-coherence is a mark of rationality or a mark of rationality in the distinctive terms currently assumed in the literature. Until substantial reasons for this revision are provided, it seems fair to conclude, we may still regard CD and similar principles as initially correct and, hence, gloss cases of ambivalence as cases of less than fully rational desiring. This is not to say that violations of $\mathrm{CD}$ ipso facto make subjects completely irrational. As emphasised earlier, $\mathrm{CD}$ is just a pro tanto condition on rationality: compliance with it makes us more rational and breach of it makes us less rational, but not necessarily on the whole rational or irrational.

In this regard, there is no relevant difference between $\mathrm{CD}$ and Consistent Belief, which is also based on the assumption that attitude coherence is a mark of rationality. As the dialetheist would be ready to argue, it may very well be that there are genuine cases of dox- 
astic ambivalence (i.e. genuine cases in which one does believe that $\mathrm{p}$ and not $\mathrm{p}$ ). That can hardly force us to conclude that, barring perhaps certain exceptional or special cases, there is no rationality norm concerning the consistency of one's beliefs (cf. Broome 2013, p. 91). Violations of Consistent Belief, most of us are ready to admit, make subjects less than fully rational believers. Of course, these violations do not, in and of themselves, make subjects completely irrational. It does not follow that Consistent Belief does not express a valid pro tanto condition on rationality.

Now, Williams also stresses two ways in which conflicting desires are different from conflicting beliefs (1973, p. 169-170). On the one hand, desires, unlike beliefs, do not tend to be weakened right after a conflict of desires is revealed:

[W]hile satisfaction is related to desire to some extent as truth is related to belief, the discovery that two desires cannot both be satisfied is not related to those desires as the discovery that two beliefs cannot both be true is related to those beliefs. (Williams, 1973, p. 169)

On the other hand, desires do not automatically disappear once discarded but may reappear and lead us to regret about what was missed. Rejecting a belief is to abandon it or to cease to have it. Not so for desires:

A rejected desire, however, can, if not survive the point of decision, at least reappear on the other side of it on one or another guise. It may reappear, for instance, as a general desire for something of the same sort as the object rejected in the decision; or as a desire for another particular object of the same sort; or-and this is the case that will concern us most-if there are no substitutes, the opportunity for satisfying that desire having irrevocably gone, it may reappear in the form of a regret for what was missed. (Williams 1973, p. 170, emphasis in original)

I suspect that much can be said as to what exactly distinguishes desires from beliefs on the aforementioned scores. It certainly seems correct to suppose, in accordance with the paragraphs just quoted, that desire would enjoy a peculiarity in the way their conflicts are actually experienced by a rational subject. These experiential aspects, however, may be in agreement with points already put forward earlier in this section. Remarkably, for instance, conflicting desires of the sort that Williams has in mind seem to involve "the discovery that two desires conflict" (Williams, 1973, p. 169), which suggests a certain kind of knowledge that both desires cannot be satisfied. But we have already seen that belief or knowledge that our desires cannot be satisfied does not necessarily involve inconsistency in one's desiring. This would explain the delayed weakening and the appearance of regret - the perseverance of discarded desire, as it were-in the phenomenology of conflicting but rational desires. However, conflicting desires in the intended sense-i.e. desires that conflict with states of belief or knowledge-do not involve inconsistent desires and hence leave CD untouched.

Finally, even if the peculiarity of conative conflict is worth investigating further, this kind of considerations would seem to reveal only important aspects of the phenomenology of desire or, at most, of the ways in which we may be less than fully rational in our ordinary desiring. They would not in any obvious way lend support to the view that conflicting or incoherent desires are rationally permissible, even in principle. 


\section{Conclusion}

Let us return to Theresa's opening example. Recall that Theresa persistently expresses her desire for Britain to leave and also to remain in the European Union. The foregoing discussion allows us to conclude that, insofar as attitude-coherence is generally a mark of rationality, and insofar as there are no obvious reasons to suspend this view in the case of desire, Theresa is indeed rationally at fault. This is not the end of the world for Theresa. She might exhibit impeccable rational capacities elsewhere and might still be on the whole a remarkably rational person. All the same, when it comes to the desirability of Britain's foreign relations, she fails to respect norms of rationality for pure desire.

We have gone over several reasons to resist a number of objections against this rendering of Theresa's case. Broadly speaking, the objections examined against CD in this paper fall under two categories: most of them succeed in describing a rationally unobjectionable situation but smuggle in an uncharitable interpretation of a subject's desires as inconsistent; some of them - as the appeal to conflicting reasons to desire or ambivalence illustrate-may be taken to succeed in describing a genuinely inconsistent desires (a genuine violation of $\mathrm{CD}$ ) but unjustifiably conclude that the conflict is rationally permissible. If this is correct, we are therefore quite in the dark as to what would be special about rational desiring that would allow contradictory desires to pass. We may conclude that, insofar as attitude-coherence is a mark of rationality, desires seem also as such subject to norms of rationality. The dismissive, broadly Humean, consensus concerning the normativity of desire must therefore be rejected.

\section{REFERENCES}

Audi, R. (2001). The architecture of reason. Oxford: Oxford University Press.

Boghossian, P.A. (2008). Is meaning normative? In P.A. Boghossian (Ed.). Content and justification: Philosophical papers (pp. 95-108). Oxford: Oxford University Press.

Bratman, M. (1987). Intention, plans and practical reason. Cambridge, MA.: Harvard University Press.

Bratman, M. (2009). Intention, practical rationality, and self-governance. Ethics, 119(3), 411-443.

Brink, D. (1994). Moral conflict and its structure. Philosophical Review, 103(2), 215-247.

Broome, J. (1999a). Can a Humean be moderate? In J. Broome (Ed.). Ethics out of economics (pp. 68-87). Oxford: Oxford University Press.

Broome, J. (1999b). Normative requirements. Ratio, 12(4), 398-419.

Broome, J. (2013). Rationality through reasoning. West Sussex: Wiley-Blackwell.

Finlay, S. (2007). Responding to normativity. In R. Shafer Landau (Ed.). Oxford studies in metaethics, Vol 2 (pp. 220-239). Oxford: Oxford University Press.

Humberstone, I.L. (1992). Direction of fit. Mind, 101(401), 59-83.

Hume, D. (2006). A treatise of human nature. In G. Sayre-McCord (Ed.). David Hume: Moral philosophy (pp. 12-184). Cambridge: Hackett.

Hubin, D. C. (1991) Irrational desires. Philosophical Studies, 62(1), 23-44.

Kolodny, N. (2005). Why be rational? Mind, 114(455), 509-563.

Lewis, D. (1988). Desire as belief. Mind, 97(387), 323-332.

Lewis. D. (1996). Desire as belief II. Mind, 105(418), 303-313.

Marino, P. (2009). On essentially conflicting desires. Philosophical Quarterly, 59(235), 274-291.

May, J. (2013). Because I believe it's the right thing to do. Ethical Theory and Moral Practice, 16(4), 791-808. 
Millikan, R. (1986). Thoughts without laws; Cognitive science with content. Philosophical Review, 95(1), 47-80.

Nagel. T. (1970). The possibility of altruism. Oxford: Oxford University Press.

Parfit, D. (2001). Rationality and reasons. In D. Egonsson, J. Josefsson, B. Petersson \& T. Rønnow-Rasmussen (Eds.). Exploring practical philosophy: From action to values (pp. 19-39). Aldershot: Ashgate.

Reisner, A. (2011). Is there reason to be theoretically rational? In A. Reisner \& A. Steglich-Petersen (Eds.). Reasons for belief (pp. 34-53). Cambridge: Cambridge University Press.

Scanlon. T. (1998). What we owe to each other. Cambridge, MA.: Harvard University Press.

Schafer, K. (2013). Perception and the rational force of desire. Journal of Philosophy, 110(5), 258-281.

Schroeder, M. (2007). Slaves of the passions. Oxford: Oxford University Press.

Searle, J. (1983). Intentionality. Cambridge: Cambridge University Press.

Sinhababu, N. (2017). Humean nature. Oxford: Oxford University Press.

Smith, M. (1994). The moral problem. Cambridge: Blackwell.

Stalnaker, R. (1984). Inquiry. Cambridge, MA: MIT Press.

Stefánsson, H.O. (2014). Desires, beliefs and conditional desirability. Synthese, 191(16), 4019-4035.

Verdejo, V.M. (2017a) Coherence without rationality, rationality without coherence. Teorema, 36(1), 2338.

Verdejo, V.M. (2017b) Reasons to desire and desiring at will. Metaphilosophy, 48(3), 355-369.

Verdejo, V.M. \& González de Prado, J. (manuscript). Interlocking content and attitude.

Wall, D. (2012). A Moorean paradox of desire. Philosophical Explorations, 15(1), 63-84.

Weller, C. (2013). Hume on the normativity of practical reason. Hume Studies, 39(1), 3-35.

Williams, B. (1973) Ethical consistency. In B. Williams (Ed.). Problems of the self (pp. 166-186). Cambridge: Cambridge University Press.

Williams, J.N. (2014). Moore's paradox in belief and desire. Acta Analytica, 29(1), 1-23.

Zangwill, N. (2010). Normativity and the metaphysics of mind. Australasian Journal of Philosophy, 88(1), 21-39.

Víctor M. Verdejo is currently a lecturer at University of Valencia. Former appointments include postdocs at University of Barcelona (LOGOS Research Group) and University College London. His work focuses on the nature of concepts and thought and lies at the intersection between the philosophy of mind, the philosophy of language and the philosophy of psychology. He has produced a prolific track record of publications in research outlets such as Erkenntnis, Synthese, Dialectica, Review of Philosophy and Psychology, Acta Analytica, Grazer Philosophishe Studien, and Theoria, among others.

AdDREss: LOGOS Research Group/BIAP (Barcelona Institute of Philosophy)/University of Barcelona. Montealegre 6-8, 4th floor, 08001, Barcelona (Spain). E-mail: vmverdejo@gmail.com 